Robertson-Kirkland, B.E. (2019) Library of Congress: Early American Sheet Music. Royal Musical Association Research Chronicle, 50, pp. 172-180. (doi: $\underline{10.1080 / 14723808.2018 .1500810)}$

There may be differences between this version and the published version. You are advised to consult the publisher's version if you wish to cite from it.

http://eprints.gla.ac.uk/166102/

Deposited on: 3 August 2018

Enlighten - Research publications by members of the University of Glasgow http://eprints.gla.ac.uk 


\title{
Library of Congress: Early American Sheet Music
}

\section{Brianna Robertson-Kirkland}

\author{
Music, University of Glasgow, Glasgow, United Kingdom
}

Brianna.Robertson-Kirkland@glasgow.ac.uk

Brianna completed her $\mathrm{PhD}$ in 2016 on the eighteenth-century castrato singer Venanzio Rauzzini and the education and career of his operatic students funded by the College of Arts Internship Scholarship. She was part of the team that established the Royal Society of Edinburgh funded Eighteenth-century Arts Education Research Network (EAERN) and works alongside Professor Kirsteen McCue on the Romantic National Song Network. This year she has also been a Visiting Research Fellow at Chawton House Library, Hampshire and the Caroline Simpson Research and Collections Library in Sydney, Australia. 


\section{Repeat the title of your article here}

The Early American Sheet Music is a digital sheet music collection curated and published by The Library of Congress. This beautiful resource provides open access to a specific classification number, M1.A1 by providing high quality images and an easy-to-use visual browsing interface. It showcases early print sheet music and copied manuscript from the United States and the colonies through 1820. However, the manner in which this digital collection has been curated highlights the changing roles and responsibilities of the library from custodian to custodian and publisher. While digital collections are enabling researchers across the world to see the resource, the curation tailors the online collection thus invoking limitations on researchers. Further questions centre on issues of copyright. While the collection is free to use for personal research and education purposes what persists is a constant confusion when it comes to downloading and performing early music found in digital collections. Performing such collections may be unique to music, but it is a serious issue that requires clarification. Using the new Early American Sheet Music resource as a centre for discussion, this article interrogates the current issues of digital music collections. ${ }^{1}$

Keywords: digitisation, sheet music, collections, library, copyright

\section{Introduction}

It is no surprise that British music should feature heavily in The Library of Congress's new digitised collection Early American Sheet Music, which include well-known British composers from the early nineteenth century including William Shield (1748-1829), Samuel Arnold (1740-1802) and Charles Dibdin (1745-1814) and popular songs such as 'The Yellow Hair'd Laddie' and 'Auld Lang Syne'. ${ }^{2}$ However, while Britain and her

\footnotetext{
${ }^{1}$ I am grateful to Dr Karen McAulay who kindly read the article and provided useful advice about text-based searching and library classifications.

${ }^{2}$ See Early American Sheet Music Collection, (online) https://www.loc.gov/collections/earlyamerican-sheet-music/about-this-collection/
} 
music cannot be separated from America's colonial history, the library have taken care to select pieces of sheet "music printed or "copied in manuscript" in the United States or the colonies through $1820^{\prime}$, which directly ties into the library's existing digitisation themes. ${ }^{3}$ So far, the digital collections of early sheet music are not concerned with making available music publications printed and purchased in Great Britain, despite such collections making up the bulk of the library's holdings prior to $1870 .{ }^{4}$ No doubt, this was the main reason for the library opting against chronological digitisation, instead prioritising those pieces with a clear American provenance. While making these valuable items widely available, the Library of Congress have clear motivations to curate a digital collection detailing the birth and growth of American publishing houses, and have chosen to leave out those sources that would arguably, allow for more international interest. In this article, I will discuss the reasons digital curation is necessary but also the issues this presents, particularly to international researchers who may not have the means to explore the physical collection. I will question if such curation ultimately jars with open access.

\section{The cost of digitisation: Integrity, Omissions and Visualisation}

The Early American Sheet Music collection consists of a concise but healthy 2492 items, which bear the classification number M1.A1. While the collection is larger than

\footnotetext{
3 'About this collection', Early American Sheet Music (online) https://www.loc.gov/collections/early-american-sheet-music/about-this-collection/

${ }^{4}$ All of the digital collections within the 'Music Division' branch have a clear USA/American colony focus with whole sections dedicated to the song 'Amazing Grace', 'Aaron Copland Collection', 'Baseball Sheet Music' and even 'Dolly Parton and the roots of country music'. In this respect, the digital collections are hugely diverse but linked by one consistent theme.
} 
others in the music division (such as the Home Sweet Home: Life in Nineteenth-Century Ohio containing only 42 pieces) targeting a specific collection with a manageable number of items is a strategic effort by the Library of Congress to better enable visual browsing rather than the age-old tradition of text-based search features that may yield many random and unhelpful results. While many libraries have incorporated live chats or email to provide researchers remote expert help in navigating potentially thousands of text search hits, visual browsing utilises the website interface, making the search process more efficient and user friendly. Thumbnail images of the resources in the collection make it obvious what the item actually is, removing the need to interpret complex terminology used to describe each item. ${ }^{5}$ The Library of Congress also includes three different view options allowing the possibility of resourceful browsing as well as giving a general overview of what the entire collection has to offer.

However, while new collections such as Early American Sheet Music are being curated with visual browsing in mind, earlier digitisation efforts such as Historic Sheet Music Collection, 1800-1922 comprising almost 8000 items and the two Music for the Nation: American Sheet Music, ca. 1820-1860 and ca. 1870-1885 containing approximately 15000 and 47000 items respectively, are not easily navigated through the new visual browsing interface. ${ }^{6}$ There are simply too many items to browse and while the filters can quicken the search process, any researcher would need to spend several hours clicking through the thumbnails to find what they seek. These collections illustrate the growth and complexity of managing the digital environment and serves as

\footnotetext{
${ }^{5}$ Laura Deal, 'Visualizing Digital Collections', Technical Services Quarterly, 32:1, (2015) 15.

${ }^{6}$ Music for the Nation (online) https://www.loc.gov/collections/american-sheet-music-1820-to$\underline{\text { 1860/about-this-collection/ }}$
} 
a legacy for the library's early ventures into the digital world. The Music for the Nation project emerged from the early digitising and distributing pilot programme called American Memory, which ran from 1990-1994. The aim of this project was to preserve library holdings; however, with the internet and digital technologies in their infancy, distribution possibilities were expensive and impractical. ${ }^{7}$ Recent innovations, including the advent of web 2.0 has allowed the American Memory project to be fully realised, providing open access for several historic documents.

While these initial efforts show the rich variety of the library's early sheet music holdings, it is obvious that at this time the digital platform had not been fully conceived. There was an apparent confusion as to whether digital collections should be thought of as a direct clone of the physical library, or as a separate entity. Scholars such as Walt Crawford were determined to ensure the latter, describing in 1999 that innovations in digital collections aimed to 'enhance and extend the library' not replace it. ${ }^{8}$ Such a response was a reaction against the grumblings of cynics, who argued that such projects were nothing more than a cost-cutting exercise, eradicating the need for the library building, staff and even the physical collection.

Almost two decades later, the digital landscape has considerably changed. If there had been any unspoken optimism that such projects would cut costs, this has proved to be a massive oversight. In fact, the rapid technological advances and distribution of digital information has placed heavy strains on government funding to

\footnotetext{
${ }^{7}$ See The Library of Congress 'About American Memory' The Library of Congress, [online] https://memory.loc.gov/ammem/about/index.html.

${ }^{8}$ Walt Crawford, Being Analog: Creating Tomorrow's Libraries, (American Library Association, 1999) 160.
} 
dedicate resources specifically for digital curation as detailed by The National Academies in 2015. ${ }^{9}$ Abandoned digitisation projects such as Google Books, which indiscriminately digitised content attempting to make all printed texts available, further demonstrate the costly impracticalities of mass digitisation. ${ }^{10}$ The realisation has led many libraries to favour quality over quantity and with this change, they have an increasing responsibility to act as both custodian of the physical items and publisher of the digital.

Staying ahead of the technology is challenging enough, but there are additional questions and considerations centring on how digital collections are curated, ensuring that any misinterpretation of the material is avoided. Such concerns highlight digital collections as separate entities bearing little impact on their physical counterparts. Yet, Suzan Alteri, curator of the Baldwin Library of Historical Children's Literature, notes that digitisation has led to an increase of activity in her library's Special Collection Reading Room. Though many might assume geriatric technophobes are the only users who engage with the physical collection, Alteri has seen an increase in users from a variety of career stages and disciplines interact with both the physical and digital collections. ${ }^{11}$ Such innovations are enhancing the visibility and use of the materials, removing elitist notions that the Special Collection Archives are for select members of the academic community.

\footnotetext{
${ }^{9}$ See National Research Council, Preparing the Workforce for Digital Curation. (The National Academies Press: Washington, DC, 2015). https://doi.org/10.17226/18590.

${ }^{10}$ Tim Wu, 'What Ever Happened to Google Books?' The New Yorker, (2015), [online] https://www.newyorker.com/business/currency/what-ever-happened-to-google-books.

${ }^{11}$ Rebeca Peacock \& Jill Wurm (ed.), The New Academic Librarian: Essays on Changing Roles and Responsibilities (McFarland: North Carolina, 2014) 137.
} 
However, can we assume that all scholars will choose or indeed be able to interact with both the physical and digital collections? Laura Deal states otherwise: 'Users' only experience of a collection will be digital and this the website interface becomes the manifestation of that collection for the users'. ${ }^{12}$ Though many projects do not require analysing an entire collection and high quality images are enough to carry out in depth research on specific musical works; as funding opportunities become more competitive and digital collections readily available there is a danger that researchers are forced to rely on the digital manifestation to the detriment of their academic research and reputation. The financial impact is a serious issue that needs some consideration, particularly in a climate where funding is both limited and competitive with few opportunities for early career and independent researchers. Limited finances including travel, accommodation and subsistence costs could potentially restrict certain researchers from engaging with physical collections. Digital collections may appear as a solution, but since items are frequently omitted, a hierarchy is established between those scholars who can afford to see both the complete physical collection and those who only can rely on the digital manifestation.

The promise of open access is that all research will be made freely available to everyone but this is a utopian notation that in reality is rarely achieved. Scholars either have to source expensive open access costs to ensure their work is made available or continue to publish via traditional means, where their work is only obtainable by subscribers. ${ }^{13}$ We should think ourselves fortunate that digitisation efforts are actively

\footnotetext{
${ }^{12}$ Laura Deal, 'Visualizing Digital Collections' (2015) 19.

${ }^{13}$ See Giandomenico Sica, Open Access: Open Problems, (Polimetrica S.A.S: Milan, 2006) for an in depth discussion on the issues with open access and the strains it is placing on academics and institutions.
} 
seeking ways to make content freely available, but as research funding moves towards the new digitisation project and abandon what has been done, how long will it be before libraries see these digital collections as a cash cow? Furthermore, there are many reasons why digital collections are curated, specifically omitting certain items. The Early American Sheet Music is the perfect example of a curated resource that benefits from a focussed online platform that enables the user to more easily identify relevant materials. The Library of Congress has certainly bought into the visual browsing concept, developing succinct theme for each of their online sheet music collections and so long as the collection is relatively small i.e. no bigger than a couple thousand items, it is a much more engaging research experience especially since so much information is encoded within the sheet music that does not lend itself to key word searches.

\section{The Google Conundrum}

Google has significantly impacted the research landscape, bringing some digital collections to the fore while others fall into obscurity. Andrew D. Asher and Lynda M. Duke observed undergraduate and postgraduate student research patterns concluding that Google is 'the preferred starting place for both every day and academic research', with the student rarely looks beyond the first search page. While large-scale databases such as Worldcat and RISM attempt to bring together a cohesive list of rare print and manuscript items across the world, the text-based searches on these sites are not as intuitive as Google, nor does every library subscribe to their database. This adds yet another area of responsibility for the library. The information for the digital collection needs to be both clear and accessible, and sit high on the Google search list, especially if the library does not subscribe to dedicated large-scale online databases.

I tested this theory with the Library of Congress's Early American Sheet Music 
collection. First of all, I typed in exact titles of items appearing in the collection and each time these appeared as the first hit, allowing me to click through to the item with ease. However, in searches where the title had slight variations, for example typing in 'The Wood Robin' rather than 'The wood robin for the piano forte adapted for the improvement of juvenile performers', the item didn't appear on the first search page at all. Adding the composer's name, 'Reginald Spofforth' did move the item up the search list; it still only appeared halfway down the first Google search hit page. Changes to the word combination or adding unique words such as 'Juvenile' increased the likelihood of the item appearing on the first search page. However, utilising these methods may not instantly appear obvious, especially to researchers who are unfamiliar with the nuances of online text-based searching.

The Early American Sheet Music collection is a high quality source that has taken care to incorporate easy visual browsing and search possibilities via the main Library of Congress website. Nevertheless, it lacks more general visibility, restricting the possibility of serendipitous discovery, particularly by students and scholars working abroad who may not instinctively think of The Library of Congress as a key custodian of digital music collections.

Even if a scholar were to stumble onto the resource via a general online search, while the Early American Sheet Music collection includes a succinct, introductory paragraph neatly setting the scope of the physical collection and the motivation for its digital curation. What is missing, however, is a clear indication of how many pieces from M1.A1 physical collection are omitted from the digital. I must admit, in my first exploration of the site, I assumed all of M1.A1 had been made available online. It was only after researching digital curation and realising that this involves a careful selection process that I was prompted to look up the main catalogue. What I discovered is that 
M1.A1 consists of total 3722 sheet music items and yet there is no indication that almost 1000 pieces have not been digitised.

This careful selection also allows the digital collection to be customised, fulfilling the Library's own publication agenda. While publishers have worked to this model for centuries, one might expect the Library to be more transparent, explicitly stating what has been made digitally available and what has not. ${ }^{14}$ The introductory paragraph could easily incorporate this information and include a link to the full catalogue, clarifying that the digital is a representation, not the collection as a whole. Neglecting such information potentially leads to a misinterpretation of the material and does not enhance the visibility of the physical collections.

\section{Domestic Collections}

The 'About' paragraph for Early American Sheet Music, while succinct focusses on the composer and the work with little discussion on domestic performance or early composite music collections. Many of these nineteenth-century pieces are arranged for voice and piano - a primary indication 'it was intended for home music-making, or 'at

home' functions'. ${ }^{15}$ Early prints of publications specifically for domestic consumption are providing valuable information about the socio-cultural world of music-making, including the gender divide, colonialism, and furthering understanding of performance practice in home music-making. Recent scholarly work including Jeanice Brooks' Sound Heritage project in partnership with Sydney Living Museums, specifically

\footnotetext{
${ }^{14}$ Patricia Puckett Sasser, 'Sounds of Silence: Investigating Institutional Knowledge of the Use and Users of Online Music Collections', Music Reference Services Quarterly, 12:3-4, (2009) 98.

${ }^{15}$ Derek Scott, The Singing Bourgeois, (Routledge: Oxford, 2001) 45.
} 
examine collections in English and Australian country houses, which demonstrate a shift in the scholarly landscape to look more broadly at collections rather than the work. $^{16}$

Historically, early print music for domestic consumption was not taken seriously by the Library of Congress. In fact, it had never been part of the library's remit to acquire 'books of entertainment' and yet, in Gillian Anderson's study of these early collections she noted that 500 volumes largely of British music had accumulated during the period 1800-1870 since 'the [acquisition] guidelines were not strictly enforced.' ${ }^{17}$ However, there is little information about where these volumes were obtained. Anderson briefly mentions the library randomly accepted gifts and purchased sheet music throughout this time, but avoids going into specific detail about who the families were, where the purchases took place and if this was of single sheets or larger bound volumes. Eighteenth and nineteenth-century composite music collections are a typical commodity to find in both Britain and the United States. While it was common practice for publishers to sell single sheets at low cost, a person (typically women) could quickly accumulate a mass of single items. Binding single sheets into a leather bound volume was a practical solution that individuals as well as institutions took advantage of. ${ }^{18}$

${ }^{16}$ See Sound Heritage (online) https://sound-heritage.soton.ac.uk/

17 John Y. Cole, 'Of Copyright, Men, and a National Library' Quarterly Journal of the Library of Congress 28 (1971) 4-5 \& Gillian B. Anderson, 'Putting the Experience of the World at the Nation's Command: Music at the Library of Congress, 1800-1917'Journal of the American Musicological Society, 42: 1 (University of California Press: California, 1989) 110.

${ }^{18}$ Maurice Rickards, The Encyclopaedia of Ephemera: A Guide to the Fragmentary Documents of Everyday Life for the Collector, Curator, and Historian (Psychology Press: New York, 2000) 295. 
Personal bound volumes are often easy to identify as the name of the person typically is written on the inside frontispiece or is stamped on the front and or the spine, providing useful evidence in identifying provenance, past owners and key information about personal taste, style and performance practice if the sheet music contains written markings. Volumes bound by a library are equally intriguing, giving insight into how the sheet music was organised. ${ }^{19}$

Many of the pieces belonging to Early American Sheet Music show evidence of having been previously bound. The ragged edge of some pieces such as 'The Wood Robin' informs an eagle-eyed scholar that the piece had been removed from a larger composite collection. ${ }^{20}$ Beautiful hand-written pencil markings appear on each piece detailing the title and composer, which is perhaps a glimmer of an old cataloguing effort. Yet there is little information on the Library of Congress's site discussing the complex history of their Early American Sheet Music collections. Much of the discussion centres on 1870 , since it was in this year the copyright law changed so that the Depository was centralised to one place - the Library of Congress.

Almost overnight acquisition by purchase became insignificant, and the source of most of the Library's music holdings changed from England to the United States.

${ }^{19}$ There are several composite music collections held in national libraries including The National Library of Scotland, The British Library, The Library of Congress among others. Many have personal inscriptions on the frontispiece or the inside of the front binding board. For examples see Sydney Living Museums, The Dowling songbook [online] https://archive.org/details/DowlingSongbook41008.

${ }^{20}$ Reginald Spofforth, The Wood Robin for the Piano Forte Adapted for the Improvement of Juvenile Performers. (1811, monographic. published by J. Paff,, between 1811 and 1817, 1811). Retrieved from the Library of Congress, <https://www.loc.gov/item/2015562453/>. 
America's legislature finally had a music collection made up largely of the product of its own press (Anderson, 1989:109).

By comparison the Music for the Nation 'About' section is much more detailed discussing the active effort the library took to develop the music collections, including the acquisition of sheet music from c. 1820-1860 transferred from the US patent office after the new copyright law was in force. In general, this level of detail is rare. In contrast to many of the other digital collections included in the Music Division, Music for the Nation developed out of a research project, enabling such detail to be included. The sparse information provided for the other digital collections could be seen as an invitation to scholars to develop research projects on items already digitised. For example, the ambiguous origins of items contained within Early American Sheet Music are precisely the kinds of projects that would inspire scholars of domestic music collections and book historians. Such a project has the potential to provide key information about the nineteenth-century practices of libraries dealing with gifts of domestic collections as well as musicological concerns.

However, the hierarchy of what is digitised and what is not, directly impacts trends in the research landscape, manipulating scholars into areas of interest. No funder wants to pay for work that has already been done and it is more advantageous to research physical collections that have not been digitised, tying in the digitisation as an output. This is common practice when applying for large-scale funds since many research bodies including Standard Research Grant offered by the Arts and Humanities Research Council (AHRC) will not fund digitisation projects that do not have a larger 
research question. ${ }^{21}$ As a result, the digital collection is representative of a culmination of research activity and while future scholars may use it to examine specific composers or works, the collection itself is not subject to further scrutiny.

What is clear is that in a digital age, with rapidly advancing technology, the research landscape is also subject to rapid changes. Making collections digitally available are a valuable resource, but some care and consideration needs to be given toward their long-term use and if money will be invested to allow further research and curation work to be carried out. This can be difficult to obtain, since research projects are limited on time and finances, forcing the library to rely on 'soft money' (money gifted from individuals or corporations) for any additional work to be carried out. ${ }^{22}$ One might assume that digital collections are easy to re-curate. Surely, changing the interface is just as simple as moving physical items around a museum space? However, with new research projects that incorporate digitisation outputs changes the hierarchy of resources, and the already digitised run the risk of becoming dusty museum items that quickly fall into the digital black hole.

Music for the Nation is a perfect example. It is an immensely useful resource, with the vast number of items demonstrating the wealth of the Library's collection, but it isn't suitable for efficient visual browsing. The recent move towards visualisation as the primary interface would surely encourage the library to re-curate the resource, dividing it into smaller more manageable sections. Even subsections would allowing for easy

21 Arts and Humanities Research Council, Research Funding Guide, 4.1 (2018) 10 [online] www.ahrc.ac.uk/documents/guides/research-funding-guide/.

22 See Aaron D. Purcell, Digital Library Programs for Libraries and Archives: Developing, Managing, and Sustaining Unique Digital Collections, (American Library Association, 2016). 
visualisation and ensure the collection remained intact. However, none of these changes have been made and the collection stands out from the rest in the music division.

\section{Performer's right to perform?}

When it comes to early sheet music collections, one of the main advantages is that the digital format rejuvenates the music for research and performance purposes. The fragility of the physical source is no longer an issue since the performer can easily download the item and play the music using a digital device or re-printing it on paper. While one may presume that the items made available on the Early American Sheet Collection can be exploited in this manner, the 'Rights and Access' section of the website contains confusing legal jargon that does not consider performance. It states that 'these materials are for educational and research purposes and makes no warranty with regard to their use for other purposes'. ${ }^{23}$ The same statement appears alongside other collections unrelated to music, though the music division does go into more detail about how permissions could be obtained, a hint that the library recognises performers will be interested in the collection for practical use. What follows is complex advice informing readers that where possible the Library has included permissions information in the bibliographic section and in all cases the Library should be consulted. What is unclear is if the physical piece of music is still under copyright or if the digitised image is subject to copyright, in which case permission from the library is all that is needed.

While one might assume that these nineteenth-century collections are not subject to copyright, the effort the library has made to obtain permissions for each item suggests otherwise. Considering the number of man hours it has taken to obtain this information

\footnotetext{
${ }^{23}$ The Library of Congress, 'Rights and Access' [online] https://www.loc.gov/collections/earlyamerican-sheet-music/about-this-collection/rights-and-access/
} 
as well as providing specialist advice to those who enquire about performing the pieces, it highlights the difficulties in making even early sheet music open access. Digitisation and copyright remains a complex, legal grey area that in recent years has prompted further scrutiny, though there is little clarity on fair use for performance. ${ }^{24}$ While diligent musicians will seek out expert help to ensure no copyright is breached, easy downloads from databases including IMSLP, Archives.org and even the Library of Congress, means that it is equally easy to ignore statements 'Rights and Access' statements. IMSLP have attempted to get round this issue by including a digital release form that pops up after requesting a download. The user is prompted to click a fair use agreement, ensuring no copyright is violated. The Library of Congress would benefit from building such a form into their interface, which would provide a clear statement that it is the responsibility of the user to seek appropriate permissions where necessary.

\section{Conclusion}

The Early American Sheet Music collection is a beautiful resource incorporating high quality images of unique sheet music items intended for domestic music-making. The digital interface is inviting and engaging, allowing even the most technologically inept to efficiently sift through the items with a clear sense of what is available. The incorporation of visual browsing has removed the necessity to understand complex library text-based search terminology and decipher descriptions of items, which may result in many hours wasted yielding limited or zero results. Unlike the Music for the Nation collection, curated in the early 2000s, which holds a vast number of resources

24 For an in depth discussion on the issues with copyright and music see Andreas Rahmatian (ed.) Concepts of Music and Copyright: How Music Perceives Itself and How Copyright Perceives Music, (Cheltenham, 2015). 
unsuited to the visual browsing interface, the Early American Sheet Music collection demonstrates innovations in digital curation. Such efforts are encouraging active engagement with the digital collection as a legitimate research resource and resolve previous issues of constant physical handling of fragile historical items. Many libraries, including the Library of Congress, highlight open access as a benefit of digitisation since it makes historical items freely available to a wider public and academic community remove elitist notions of the Special Collections Reading Room.

However, the manner in which the digital collection has been curated raises bigger questions and concerns about the future research landscape. While there are several reasons why it is impractical to create a digital clone of the physical collection, the library is no longer a mere custodian of items. The digital collection is curated and refined to fulfil specific agendas and unless the library is transparent about the process of curation and why certain items have been omitted there is a danger that the collection could be misinterpreted invalidating the digital resource and further establishing a hierarchy in the research landscape. To put it plainly, publishers will become highly aware when researchers only utilise digital resources and will question the integrity of the researcher without considering circumstances that led to a lack of engagement with the physical collection. Funding bodies and libraries need to ensure they work side-byside so that funding to see the physical collections remains available and that this is not slowly reduced or removed as more digital collections appear online.

As technology advances and the digital collections become even more sophisticated an added danger is that institutions are enticed to capitalise on the commodity. Some digital collections including Eighteenth-Century Collections Online and Alexander Street Press are already only available by subscription, forcing institutions to bear high level costs and only to provide access to students and members 
of staff. The current employment landscape for academia is so competitive that early career and independent researchers who lack institution support heavily rely on open access resources, whether it is to carry out research, create projects or stay on top of emerging scholarship. Open access may promise to eradicate elitisms, bringing heritage resources and scholarship to the people, but as institutions feel the financial squeeze, how long will it be before the digital collection is locked away in a bank vault where only those with the cash have access? 